\title{
História, consciência e inconsciente: o sujeito na Análise do Discurso
}

\section{Belmira Rita Magalhães}

Socióloga, doutora em Letras e professora dos Programas de Pós-graduação em Ciências Sociais e em Letras e Lingüistica da Ufal.

Resumo: Discussão da concepção de sujeito na Análise do Discurso, com base nas noçōes de história, consciente e inconsciente e em referenciais teórico-metodológicos do Materialismo Histórico e da Teoria do Discurso, capazes de possibilitar a compreensão do lugar histórico do sujeito, que se constitui pela sua determinação social e pela possibilidade de imprimir sua marca no discurso, embora sem total controle sobre ele; e investigação de que resulta uma apreensâo de um sujeito ideológico duplamente marcado (ou atravessado) pelo consciente e pelo inconsciente, destacando-se a possibilidade de um sujeito que, determinado pelos conflitos sociais e condicionado pelo inconsciente, mesmo assim faz história.

Palavras-chave: consciente/inconsciente; sujeito; discurso; história

\section{Ma.. do Socorro Aguiar de 0.} CAVALCANTE

Doutora em Lingūística, na área de Análise do Discurso, professora dos Programas de PósGraduaçāo em Educação (PPGE, Cedu) e em Letras e Lingüistica da Ufal (PPGLL, Fale).

Resumen: Discusión de la concepción de sujeto en el Análisis del Discurso, con base en las nociones de Historia, consciente e inconsciente y en referenciales teórico-metodológico del Materialismo Histórico y de la teoría del discurso, capaces de posibilitar la comprensión del lugar histórico del sujeto, que se constituye por su determinación social y por la posibilidad de imprimir su marca en el discurso, aunque sin total control sobre él. De esa investigación resulta la aprensión de un sujeto ideológico doblemente marcado (o atravesado) por lo consciente y el inconsciente, destacándose la posibilidad de un sujeto que, determinado por los conflictos sociales y condicionado por el inconsciente, aun asi hace historia.

Palabras-clave:consciente/inconsciente; sujeto; discurso; historia 

Embora muitos estudos acerca da questão do sujeito já tenham sido desenvolvidos, em se tratando da Análise do Discurso (em suas diversificadas vertentes), esta ainda é uma questão aberta, por sempre suscitar polêmicas, desdobramentos teórico-práticos que produz, diferentes posições teóricas sob as quais é abordada - o estruturalismo saussuriano, a psicanálise lacaniana, o materialismo estruturalista francês, a pragmática e o materialismo histórico dialético — , só para citar alguns.

Assim, como já dissemos em outro momento, diferentes posições teóricas possibilitam diferentes olhares sobre o mesmo objeto de estudo. Nesse sentido, entendemos ser necessário expressar nossa compreensão acerca do tema, destacando o lugar teórico de onde falamos e, conseqüentemente, o nosso ponto de vista. Não temos, neste trabalho, a pretensão de examinar os campos teóricos referidos - o do sujeito individualista representado pela fenomenologia e pelo interacionismo simbólico; o do sujeito assujeitado, que, de acordo com a perspectiva estruturalista, pode ser assujeitado pela estrutura social, pela estrutura lingüística e pela estrutura do inconsciente. Esses são alguns elementos característicos das posições supracitadas a que nos referimos, apenas para estabelecer um contraponto à filiação teórica que assumimos e perante a qual abordaremos a questão do sujeito. Tomaremos o caminho de uma terceira vertente que vem ganhando espaço no terreno das ciências sociais, representada por teóricos como Bakhtin, Lukács, Leontiev, Duarte, Magalhães, além de outros que adotam o referencial teórico do materialismo dialético, nos estudos da linguagem.

\section{Consciência}

A consciência é um conhecimento das coisas e de si e um conhecimento desse conhecimento (reflexão). Leontiev (2004, p. 94), em seu estudo sobre as condições de aparecimento da consciência, fornece-nos significativa contribuição quando afirma que 
A consciência só podia aparecer nas condições de uma ação efetiva sobre a natureza, nas condições de uma atividade de trabalho por meio de instrumentos, a qual é ao mesmo tempo a forma prática do conhecimento humano. Nestes termos, a consciência é a forma do reflexo que conhece ativamente. [...] É o reflexo da realidade, refratada através do prisma das significações e dos conceitos lingüísticos, elaborados socialmente. [...] É a forma histórica concreta de seu psiquismo. Ela adquire particularidades diversas segundo as condições da vida dos homens e transforma-se na seqüência do desenvolvimento das suias relações.

É, pois, a consciência que fixa as aquisições e os resultados alcançados a cada momento pela humanidade, confronta essas aquisições com a realidade e transforma o adquirido (apropriado) em base para a produção do novo. Adquire forma e existência nos signos criados pelos indivíduos, no processo de trabalho em que, agindo sobre a natureza, os homens a transformam e se transformam, ao mesmo tempo em que (inter)agem com e sobre outros homens nas suas relações sociais. Os signos são, pois, o alimento da consciência e só emergem no processo de relação entre os indivíduos. A forma concreta sob a qual opera a consciência da realidade circundante é a linguagem, cujo nascimento é conseqüência da atividade produtiva dos homens.

Essa atividade se desencadeia em duas direções: na ação dos homens sobre a natureza, apropriando-se de meios de satisfazer suas necessidades, e na necessidade de se comunicar com outros homens - conseqüência da atividade produtiva. Em Marx (1975, p. 159), temos que "a linguagem é tão velha como a consciência, a linguagem é a consciência real, prática, que existe também para outros homens, que existe, portanto, então, para mim também".

Apoiado nessa afirmação de Marx, Leontiev (op. cit, p. 92) acrescenta que 
Tal como a consciência, a linguagem é o produto da coletividade, o produto da atividade humana, mas é igualmente "o ser falante da coletividade" (Marx); é apenas por isso que existe igualmente para o homem tomado individualmente.

Ou seja, a percepção e a efetivação das relações sociais só são possíveis através da linguagem, já que sem linguagem não há consciência. Entretanto, como já foi dito anteriormente, as formas de manifestação da consciência não são idênticas; variam de acordo com as relações sociais que o indivíduo estabelece, sendo seu grau de clareza proporcional ao grau de orientação social em que o sujeito se insere.

Como nos diz Bakhtin (1981, p. 115), "quanto mais forte, mais bem organizada e diferenciada for a coletividade no interior da qual o indivíduo se orienta, mais distinto e complexo será seu mundo interior."

Diante do exposto, podemos concluir que a consciência tem origem social; tem a linguagem como material de expressão semiótica; manifesta-se em níveis. Tomando as categorias marxianas de "em si" e "para si", utilizadas por Duarte (1993), teremos, de acordo com o nível de manifestação, a consciência em sie a consciência para si.

Consciência em si é a consciência vivida, mas não reflexiva, na qual o sujeito tem uma vaga e confusa percepção de si mesmo e do que se passa à sua volta. Apropria-se das objetivações genéricas, sem manter uma relação consciente com elas. Ou seja, o indivíduo se apropria da linguagem e, através dela, se objetiva; relaciona-se com instrumentos, aprende a utilizá-los, produz novos objetos, sem ter consciência plena de que a linguagem, os instrumentos, os objetos são produtos humanos e de que suas objetivações (do indivíduo) também estarão a serviço da humanidade e serão por ela apropriadas. 
Já consciência para si é a consciência ativa e reflexiva na qual o sujeito tem consciência de pertencer ao gênero, de com ele relacionar-se. É capaz de reconhecer a diferença entre si e o gênero, de direcionar sua ação em função dos valores genéricos que assume.

\section{A constituição do sujeito na/pela linguagem.}

Sendo a linguagem uma das objetivações genéricas que constituem a base do desenvolvimento humano, tentaremos, de agora em diante, tecer considerações acerca das relações que os indivíduos estabelecem com essa objetivação. Segundo Duarte (1993, p. 137-138),

A atividade vital humana, sendo originariamente coletiva, exige, portanto, a atividade comunicativa. A atividade de comunicação foi, ao longo da história primitiva, se objetivando em processos que geraram a linguagem.[...] Sem apropriar-se da linguagem, dos objetos e dos usos e costumes ninguém pode existir enquanto ser humano.

A linguagem, como a consciência, é, pois, um fato social, uma vez que resulta do processo de apropriaçãoobjetivação dos produtos humanos historicamente acumulados. Conforme dissemos anteriormente, sem consciência não há percepção da generidade e, sem linguagem, não há consciência. É através da linguagem que os indivíduos se apropriam da realidade e da própria linguagem, de conceitos que lhes permitem entender os fenômenos e agir no mundo. Essa forma de objetivação se objetiva por via do discurso.

Nessa perspectiva, o discurso não é pensado como um bloco uniforme, mas como um espaço marcado pela heterogeneidade de "diversas vozes", vindas de outros discursos - o discurso de outro (interlocutor) posto em cena pelo enunciador ou o discurso do enunciador colocando-se em cena como um outro. Nesse sentido, o sujeito traz em si todas as vozes que o antecederam, um 
mundo que já foi articulado, compreendido diferentemente. A linguagem está sempre em movimento, sempre inacabada, susceptível de renovação pela dependência da compreensão que acontece no diálogo, no qual se constitui a singularidade, pelo fato de a intersubjetividade ser anterior à subjetividade e de a relação entre interlocutores ser responsável pela construção de sujeitos produtores de sentidos.

O dialogismo vem estabelecer, portanto, uma ruptura tanto com a visão de sujeito fonte, infenso à inserção social, como com a visão de sujeito assujeitado, submetido ao ambiente sócio-histórico. É com base nessa perspectiva que defendemos um sujeito constituído nas práticas sociais concretas, por elas condicionado, mas também capaz de fazer escolhas, não qualquer uma, mas dentro das possibilidades permitidas pela objetividade; capaz de intervir na realidade e essa intervenção será tão mais adequada e eficaz quanto maior for o conhecimento que essa subjetividade tiver da objetividade posta.

Essas afirmações encontram respaldo também em Lukács, para quem o homem é um ser que reage às demandas postas pela realidade objetiva, um ser que dá respostas a necessidades determinadas. Diz o referido autor (1978, p. 5),

O homem torna-se um ser que dá respostas, precisamente na medida em que - paralelamente ao desenvolvimento social e em proporção crescente - ele generaliza, transformando em perguntas seus próprios carecimentos e suas possibilidades de satisfazê-los; e, quando, em sua resposta ao carecimento que a provoca, funda e enriquece a própria atividade com tais mediações, freqüentemente bem articuladas.

Reagindo a alternativas colocadas pela realidade objetiva, o sujeito o faz aceitando-as, delas discordando, modificando-as, retendo certos elementos nelas existentes, 
transformando-as em novas perguntas para as quais vai procurar respostas. É essa atividade que vai orientar a ação do sujeito, sem, no entanto, o anular, pois, sendo um ser que responde ao seu ambiente, o faz dando as respostas possíveis naquele momento, em função dos limites e possibilidades que a realidade objetiva lhe oferece. Essas respostas podem, no momento subseqüente, se transformar em novas perguntas e, assim, sucessivamente, de tal modo que tanto o conjunto de perguntas quanto o de respostas vão formando gradativamente os vários níveis de mediações que aprimoram e complexificam a atividade do homem, bem como enriquecem e transformam sua existência.

Pêcheux, através do conceito de esquecimento 2, trabalha o desejo/possibilidade de a subjetividade controlar o sentido do discurso, ao dizer que

Desse modo se acha, pois, desenhado num espaço vazio o campo de "tudo o que teria sido possível ao sujeito dizer (mas que não diz) ou o campo de "tudo a que se opõe ao que o sujeito disse". Essa zona do rejeitado pode estar mais ou menos próxima da consciência e há questões do interlocutor - visando a fazer, por exemplo, com que o sujeito indique com precisão "o que queria dizer" - que o fazem reformular as fronteiras e re-investigar essa zona. Propomos chamar este efeito de ocultação parcial esquecimento 2 e de identificar aí a fonte de impressão de realidade do pensamento para o sujeito ("eu sei o que digo" "eu sei do que falo") (GADET; HAK, 1993, p. 176)

Portanto, para esse autor, a partir do mecanismo constitutivo de sujeito que ele denominou de esquecimento 2 , o sujeito exerce as potencialidades da consciência para fazer as escolhas necessárias ao projeto de tornar seu discurso o mais claro possível. Nesse sentido, a consciência, que para ele não pode estar dissociada do inconsciente, 
pressupõe o sujeito que decide, que faz escolhas, que busca seu lugar no mundo:

Todo discurso é o índice potencial de uma agitação nas filiações sócio-históricas de identificação, na medida em que ele constitui ao mesmo tempo um efeito dessas filiações e um trabalho (mais ou menos consciente, deliberado, construído ou não, mas, de todo modo, atravessado pelas determinações inconscientes) de deslocamento no seu espaço (PÊCHEUX, 1990, p. 56).

Nesse trecho, Pêcheux já afirma que a identificação discursiva se dá pelas filiações sócio-históricas, admitindo uma agitação no interior delas. A práxis (trabalho) torna possível, sempre de forma consciente e inconsciente, o deslocamento do sujeito. O sujeito busca o controle de seu dizer, instalando a possibilidade de criação do novo e não de seu aprisionamento total à ideologia e ao inconsciente. O trabalho do sujeito, para Pêcheux, se dá em todos os lugares discursivos e não em determinados lugares privilegiados, preestabelecidos.

De passagem, os estruturalistas acreditavam assim na idéia de que o processo de transformação interior aos espaços simbólicos é um processo EXCEPCIONAL: o momento do herói solitário e do poético (Marx/ Marllamé), como trabalho extraordinário do significante (PECHEUX, 1990, p. 52).

Para esse autor, ao contrário, toda identificação carrega a possibilidade de crítica, de negação do estabilizado:

Não há identificação plenamente bem-sucedida, isto é, ligação sócio-histórica que não seja afetada, de uma maneira ou de outra, por uma "infelicidade" no sentido performativo do termo, isto é, no caso, por um erro de pessoa, isto é, sobre o outro, objeto da identificação (PÊCHEUX, 1990, p. 57). 
Seguindo seu pensamento, Pêcheux afirma ainda, em Estrutura e acontecimento, que há, por parte do sujeito, tomadas de posição que têm a ver tanto com as escolhas a que Lukács se refere, como com o intuito discursivo que Bakhtin assegura ao sujeito. Ao terminar seu livro, Pêcheux, a nosso ver, sem negar as determinações da história, alerta para a importância do acontecimento e, nele, o lugar do sujeito:

A posição de trabalho [...] supõe somente que, através das descrições regulares de montagens discursivas, se possam detectar os momentos de interpretações enquanto atos que surgem como tomadas de posição, reconhecidas como tais, isto é, como efeitos de identificação assumidos e não negados (ibidem).

Como se percebe, o sujeito de Pêcheux toma posição, assumindo ou negando identificações, embora, em nenhum momento, se possa deixar de perceber que esses deslocamentos somente são possíveis a partir do que a realidade social oferece, isto é, do que a objetividade permite ao sujeito escolher.

A compreensão do que estamos discutindo só se torna possível na perspectiva do materialismo históricodialético, nunca pela concepção estruturalista, pois aquela concebe o sujeito determinado pelas condições históricosociais e condicionado pelo inconsciente, que também é histórico. A radicalidade do pensamento de Marx está calcada na afirmação de que tudo que é humano é ontologicamente histórico e social.

Nesse sentido, o discurso não é uma construção independente das relações sociais, mas, ao contrário, o fazer discursivo é uma práxis humana que só pode ser compreendida a partir do entendimento das contradições sociais que possibilitaram sua objetivação. Pêcheux enfatiza esse fato em todos os seus textos, ao submeter a formação discursiva às formações ideológicas que, por 
sua vez, expressam as contradições de classes antagônicas da sociedade.

Enfatizar que o sujeito não é fonte de seu discurso é um passo importantíssimo, mas não suficiente, pois pode significar a anulação da práxis, isto é, inibir a capacidade de transformação de produção do novo que só o sujeito possui. Essa capacidade de conhecer, própria do sujeito, é, necessariamente, atravessada pela ideologia, isto é, pelas possibilidades de interpretação que a sociedade dividida em classes oferece aos sujeitos. ' Para Lukács, seguindo os passos de Marx, não há uma ideologia a priori, sem historicidade, pois "toda ideologia tem seu serprecisamente-assim social: ela nasce direta e necessariamente do hic et nuncsocial dos homens que agem socialmente na sociedade" (VAISMAN, 1989, p. 446), o que significa dizer que a ideologia só tem existência social e que ela se refere a uma realidade específica sobre a qual atua. Nesse sentido, "a ideologia é, acima de tudo, aquela forma de elaboração ideal da realidade que serve para tornar a práxis social dos homens consciente e operativa" (LUKÁCS apud VAISMAN, p. 446).

Cada sociedade construirá formas ideológicas de lidar com os conflitos, pois sempre haverá "conflitos entre a comunidade e os indivíduos, porque seria um preconceito metafísico pensar que a consciência social fosse totalmente idêntica em cada homem" (VAISMAN, 1989, p. 456). Sintetizando, a relação entre subjetividade e objetividade, isto é, entre um sujeito com linguagem, consciente/ inconsciente, é necessariamente histórica.

Podemos afirmar que, para a criação do novo, necessário se faz que as mudanças cheguem até a consciência, para conservá-las e promover a reprodução através da generalização social. É nesse processo que a linguagem cumpre uma de suas funções: fixar na consciência as aquisições, conservando-as e superando-as, a partir do desenvolvimento de novas perguntas e novas respostas.

A nosso ver, o escopo teórico marxiano dá um passo decisivo para estabelecer o papel da subjetividade
${ }^{1}$ Estamos, neste artigo, sempre nos referindo às sociedades de classe. Essas colocações em sociedades sem classe precisam ser desenvolvidas de forma diferente. 
na construção do ir-sendo do ser social, ou seja, é a subjetividade que instaura a possibilidade de um mundo humano/social, mas não uma subjetividade autônoma que se impõe idealmente à realidade. Na verdade, tem-se uma subjetividade objetivada, isto é, um sujeito que possui história, por isso, limites na construção ideal e efetiva de suas realizações.

Entretanto, o fato de o sujeito não absolutizar a capacidade de criar o que quiser, segundo sua vontade, única e exclusiva, não retira da subjetividade a capacidade criadora, nem a importância crucial de sua ação para a reprodução do ser social. Assim é que não há uma individualidade, nem produção individual que não sejam essencialmente sociais e históricas.

Nossa intenção é, pois, trazer para o debate a noção de ideologia de Marx e Lukács, que afirmam que a ideologia nasce diretamente do cotidiano dos seres sociais em sua atuação na sociedade e que ela só tem, pois, existência histórico-social se referida sempre a uma realidade específica sobre a qual atua. A nosso ver, a interpelação ideológica e inconsciente, defendida por Althusser e Lacan, retira do sujeito a possibilidade de uma reflexão consciente sobre sua própria história, única possibilidade de o sujeito propor respostas que contrariem as existentes, trazendo a criação do novo como matriz da sociabilidade humana, como afirma o materialismo histórico-dialético. 


\section{Referências}

BAKHTIN, Mikhail. Marxismo e filosofia da linguagem. Trad. de Michel Lahud e Yara Frateschi Vieira. São Paulo: Hucitec, 1990.

CAVALCANTE, Maria do Socorro Aguiar de Oliveira. A língua sob o olhar da Análise do Discurso. In: MOURA, Maria Denilda (Org.). Os múltiplos usos da língua. Maceió: Edufal, 1999.

- Qualidade e cidadania nas reformas da educação brasileira: o simulacro de um discurso modernizador. Maceió, Edufal, 2009.

LEONTIEV, Aléxis. O desenvolvimento do psiquismo. São Paulo: Centauro, 2004.

LUKÁCS, Georg. A reprodução. Trad. de Sérgio Lessa. Maceió, 1992. mimeo.

LUKÁCS, Georg. Os princípios ontológicos fundamentais de Marx. Trad. de Carlos Nelson Coutinho. São Paulo: Ciências Humanas, 1979.

MAGALHÃES, Belmira et al. Da linguagem ao poder. Maceió: Edufal, 1997.

MAGALHÃES, Belmira. A leitura do mundo e o ensino da língua. In: MOURA, Denilda. (Org.). Língua e ensino: dimensões heterogêneas. Maceió: Edufal, 2000.

MAGALHÃES, Belmira Rita Costa. O sujeito do discurso: um diálogo possível e Necessário. In: VOESE, Ingo (Org.). Linguagem em discurso. Santa Catarina: Unisul, 2003. v. 3. número especial.

MARX, Karl. Elementos fundamentales para la crítica de la economia política. (Grundisse). 1857-1858. México: Siglo XXI , 1978.

MARX, Karl. A ideologia alemã. Trad. de Waltensir Dutra e Florestan Fernandes. Rio de Janeiro: Zahar, 1965. 
MÉSZÁROS, István. Filosofia, ideologia e ciência social: ensaios de negação e afirmação. São Paulo: Ensaio, 1993.

PÊCHEUX, Michel; FUCHS, Catherine. A propósito da análise automática do discurso: atualização e perspectivas. In: GADET, F; HAK, T. (Orgs.). Por uma análise automática do discurso: uma introdução à obra de Michel Pêcheux. Campinas: Editora da Unicamp, 1993.

PÊCHEUX, Michel. Semântica e discurso: uma crítica à afirmação do óbvio. Campinas: Editora da Unicamp, 1988.

PÊCHEUX, Michel. Odiscursa estrutura ou acontecimento. Trad. de Eni Orlandi. São Paulo: Pontes, 1990.

VAISMANN, Ester. A ideologia e sua determinação ontológica. Ensaio, S. Paulo, n. 17-18. 